IGOR LOCROIX

\title{
ARTE COMO ESQUEMATIZAÇÃO DO MUNDO
}

\section{Igor Locroix}

igorlacroix@gmail.com

\section{NIETZSCHE, HEIDEGGER, NIETZSCHE}

Heidegger desvela, em Vontade de Poder como Arte, primeira parte da obra Nietzsche - I, e sistematiza as prinicipais definições que estão presentes nos fragmentos que originariam o trabalho central de Nietzsche, que não chegou a ser concluída, a saber, Vontade de Poder. Heidegger gira em torno de duas ideias que são interligadas: ente e ser, o ente estante e o serestar, que pode ser entendido como a realidade ontológica temporal, impermanente. Ser-estar e apresentado como aquilo que os homens, e todos os outros entes, verdadeiramente são, o que não é confundindo com deus ou com qualquer outra realidade metafísica.

Ainda, ao pensar os termos usados por Nietzsche, Heidegger define a vontade de poder como "a designação do que perfaz o caráter fundamental de todo ente" (HEIDEGGER, 2010, p. 06), o que nas palavras de Nietzsche se apresenta o fato derradeiro ao qual podemos aceder. O objetivo de Heidegger é tornar distinta a posição fundamental de Nietzsche quando ele responde à questão diretriz da filosofia metafísica: o que é o ente? E ele cumpre com esse objetivo na medida em que confronta a filosofia de Nietzsche, uma vez que acredita que a confrontação "é a maneira suprema e única de apreciar verdadeiramente um pensador" (Idem, p. 08). A confrontação estabelecida em Vontade de Poder como Arte é vista a partir da citação: "O pensamento abstrato é, para muitos, uma fadiga - para mim, em dias bons, ele é uma festa e uma inebriez" (Idem, p. 08). Heidegger entende Nietzsche não como um pensador rigoroso, mas um filósofo poeta, um filósofo da vida, e tratará sobre esse conceito de inebriez em sua relação à criação artística de maneira mais ampla quando o relacionar ao processo de criação em geral.

Para a pergunta 'o que é o ente?', existe a procura pelo ser do ente. Todo ser é um devir para Nietzsche. Todavia, esse devir tem o caráter da ação e da atividade do querer enquanto que em sua essência, a vontade é vontade de poder. Na medida em que levanta a questão a respeito do ente, Heidegger, portanto, introduz a pergunta fundamental da filosofia: o que é o ser? Durante este caminho, faz o apontamento das três posições fundamentais que entende a partir da filosofia nietzscheana: 1 - filosofia do eterno retorno: uma tentativa de reavaliação de todos os valores, "a doutrina do eterno retorno como martelo na mão dos 
IGOR LOCROIX

homens mais poderosos" (Idem, p. 18); 2 - vontade de poder: tentativa de reavaliação de todos os valores; 3 - reavaliação de todos os valores.

Heidegger estabelece uma espécie de princípio lógico com uma tese: eterno retorno (ser), uma antítese: vontade de poder (ente) e uma síntese: reavaliação de todos os valores. Neste sentido a conjugação do eterno retorno à vontade de poder ao longo do tempo é o que define o ser-estar. "O que é e como é a própria vontade de poder? Resposta: o eterno retorno do igual" (Idem, p. 19). Heidegger afirma que para Nietzsche não é possível haver disjunção entre o eterno retorno e a vontade de poder, pois a própria definição do ser é a conjugação dessas duas doutrinas ao longo da história.

O que está em questão de forma mais acentuada em Nietzsche é a instauração de valores que determinem como o ente deve ser. Entra aí a questão do niilismo que significa: “os valores supremos se desvalorizam” (Idem, p. 26). O niilismo, dentro do pensamento nietzscheano, não representa uma espécie de revolução salvadora, representante do bem, é, na verdade, algo que sempre existiu, desde antes de Cristo, e continuará a existir a partir do presente. Heidegger, e o próprio Nietzsche, estabelece nesse ponto a inversão como principal estrutura do modo de pensar nietzscheano. Uma característica do processo de inversão aparece em comparação a Schopenhauer que:

\footnotetext{
Interpretou a essência da arte como um 'quietivo da vida' enquanto tal, o que aquieta a vida em sua miserabilidade e em seu sofrimento, o que suspende a vontade cujo ímpeto provoca justamente a miséria da existência. Nietzsche inverte Schopenhauer e diz: a arte é o 'estimulante' da vida, algo que incita e eleva a vida" (Idem, p. 29).
}

Outro exemplo do processo de inversão se encontra presente na citação de Nietzsche: "A verdade é um tipo de erro, sem o qual uma determinada espécie de ser vivo não poderia viver" (Idem, p. 29). Essa citação só pode ser compreendida de forma aprofundada, uma vez que se parte da perspectiva do platonismo, no entanto, esse procedimento de inversão dos valores é presente em diversas ocasiões do pensamento de Nietzsche. Heidegger coloca a questão da vida, o que para Nietzsche é o mesmo que vontade de poder: "ela mesma é o fundamento, o princípio da instauração de valores. Então não é um dever que determina o ser, mas o ser que determina um dever" (Idem, p. 31). Portanto, antes de afirmar uma possível instauração de novos valores, é preciso omprovar a vontade de poder como caráter fundamental do ente através de todos os seus âmbitos e esferas.

Para demonstrar que o questionamento a respeito do ser-estar do ente estante não é gratuito, que na verdade ele advém de um contexto filosófico mais amplo, Heidegger 
IGOR LOCROIX

apresenta as definições presentes em diversos pensadores alemães como: Schopenhauer, Schelling, Hegel, Leibniz. No entanto, com essa apresentação ele não quer dizer que há uma dependência do pensamento de Nietzsche, mas que todos os grandes pensadores pensam sempre o mesmo numa espécie de encadeamento de um conceito que nunca se exaure. Heidegger propõe que Nietzsche não faz distinção entre vontade e vontade de poder, pois no fundo dentro dessa expressão, poder não quer dizer "um complemento da vontade, mas significa uma elucidação da essência da própria vontade" (Idem, p. 40). Heidegger explica que para Nietzsche a vontade, que usualmente é associada à alma e, portanto, àquilo que é psíquico, é também associada ao corpóreo e ao espiritual. Explica também que "a vontade é considerada como um tipo de causa" (p. 36), uma espécie de "faculdade causante" (Idem, p. 36) produtora de efeitos, ou seja, a vontade associada ao fazer, ao agir. A vontade de poder pode ser entendida como uma direção consciente, uma decisão, que ruma ao poder, que é entendido como um poder-fazer, poder-executar, poder-entificar.

$\mathrm{O}$ argumento que se fundamenta a partir dessas proposições é que para Nietzsche a vontade é um afeto, uma paixão, um sentimento. A vontade está associada à percepção do nosso corpo e espírito, que são entendidos em conjunto como uma estrutura que filtra nossa vontade. O corpo e o espírito são como parâmetros que influenciam nossa apreensão do mundo, mas que também nos induzem ao estabelecimento daquilo que queremos em nossas vidas. O querer é entendido aqui como um direcionar-se a algo, diferente do desejar compreendido como um simples querer-ter, um aspirar algo ordinário. A vontade de poder é entendida como um afeto, as consequencias da vontade de poder como aquilo que nos afeta. consciência, não representando um estado de superposição do corpo sobre a mente. Neste sentido, os sentimentos nos alçam "para além de nós mesmos" (Idem, p. 43), a vontade é, portanto, o sentimento dos seres em estado de excitação, lançados para além deles mesmos. Não "podemos nos decidir a ter uma vontade, no sentido de que poderíamos nos arrogar uma vontade; pois toda a decisão se mostra como o querer mesmo" (Idem, p. 44). Nesse sentido há uma contraposição do conceito nietzscheano emocional de vontade ao conceito 'idealista'. A ideia entendida por Heidegger como representação se relaciona à aspiração, e a aspiração não sabe o quer, porque ela não quer absolutamente, aspira a uma representação da coisa. A aspiração em contraposição à vontade que é um comando em direção à coisa em si.

Heidegger expressa que a visão idealista observa a vontade antes como uma aspiração, ou seja, como uma representação da coisa em questão. Já Nietzsche propõe que isso é uma visão limitada, que antes de mais nada existe um sentimento que nos coloca em direção a alguma coisa, antes mesmo da aspiração à representação da coisa. Heidegger reune em uma 
IGOR LOCROIX

única definição as determinações da vontade de maneira a criar uma espécia de gradação de valores por nível de excitação do ente:

Vontade como assenhoreamento sobre... que se estende para além de si, vontade como afeto (o acometimento excitante), vontade como paixão (o arrebatamento expansivo em direção à amplitude do ente), vontade como sentimento (disposição para ater-se-a-si-mesmo) e vontade como comando (Idem, p. 54).

O problema é que a compreensão da vontade é vazia em si mesma e, para Nietzsche, ela se confunde com a definição de poder, pois a vontade em essência sempre aparece como "querer-ser-mais" (Idem, p. 55). O exemplo disso vem de um dos fragmentos próprio Nietzsche:

\footnotetext{
Tomemos o exemplo mais simples, o exemplo da alimentação primitiva: o protoplasma estende seus pseudópodes para procurar por algo que se lhe contraponha - não por fome, mas por vontade de poder. Então, ele tenta superá-lo, apropriar-se dele, incorporá-lo: - O que se denomina 'alimentação' é meramente um fenômeno secundário, uma aplicação prática daquela vontade originária de se tornar mais forte. (Idem, p. 56).
}

Heidegger, portanto, com a citação acima, fecha um ciclo de sua compreensão acerca do pensamento do filósofo de Röcken. A partir desse ponto ele inicia um discurso voltado à compreensão da arte, mas de certa forma se apropriando da obra de Nietzsche para construir um argumento próprio sobre a arte.

\section{DISCURSO SOBRE A ARTE}

O objetivo principal é considerar a arte com um valor a mais do que a verdade, entendida como fruto do platonismo, que é o discurso que até os dias atuais tem uma popularidade a mais, ou seja, prepondera sobre a maioria dos discursos alternativos, mas que no fim das contas está errado. "O fenômeno artista ainda é o mais facilmente transparente... isto é, o maximamente acessível para nós mesmos, é o fenômeno artista - o ser artista" (Idem, p. 63). Heidegger. diz: "Ser artista é uma forma de vida" (Idem, p. 64). Ainda, Heidegger citando Nietzsche “denomina 'a vida a forma mais conhecida do ser'. 'Ser-estar' mesmo só é válido para ele 'como universalização do conceito de vida (respirar), ser animado, querer, atuar, devir..." (Idem, p. 64). No caso, essa postura de Heidegger, também enquadra o pensamento de Nietzsche dentro do processo de inversão, uma vez que a verdade é o que até hoje tem valor a mais do que a arte. A iniciativa artística está, para a maioria dos artistas, na 
IGOR LOCROIX

maioria das vezes, em contradição com a sua própria realidade, talvez, porque o discurso artístico seja mais frágil em termos de poder. Portanto, Heidegger não deixa de ser minimamente romântico, no sentido de estabelecer um discurso em contradição ao discurso mais poderoso, assim como Nietzsche o fez em seu tempo.

Não fica de lado a própria relação, estabelecida por Heidegger, de cinco sentenças sobre a arte. A primeira delas diz: "a arte é a figura mais transparente e conhecida da vontade de poder" (Idem, p. 65). A segunda sentença, "a arte precisa ser concebida a partir do artista" (Idem, p. 65), estabelece a inversão da estética feminina, até os dias de hoje regente de termos de poder de discurso, para uma estética masculina, ou seja, propõe a inversão de uma estética de quem recebe a arte; quem critica a arte, para uma estética de quem a produz. Nietzsche é quem propõe essa inversão, colocando o artista acima do sujeito que recebe a arte. A terceira sentença poderia ser compreendida como uma desambiguação do conceito de arte, que no caso não é meramente entendido como belas-artes, mas compreendido a partir da etimologia grega onde não havia distinção entre o conceito de arte e conhecimento. "De acordo com o conceito ampliado de artista, a arte é o acontecimento fundamental de todo ente; o ente é, na medida em que é, algo que se cria, algo criado" (Idem, p. 66). Conhecimento enquanto criação equivalente à criação artística, mas que segundo o discurso dos dois pensadores em questão tem mais valor do que a verdade.

Nietzsche levanta a questão do filósofo-artista que exerce na filosofia uma vontade de aparência, de ilusão, de engano, de devir e de mudança, que é mais profunda do que a vontade de verdade, entendida a partir da concepção de mundo supra-sensível estabelecida pelo platonismo. Nesse sentido, o filósofo-artista é um filósofo do contramovimento à tradição metafísica, pois propõe que o mundo sensível é que tem mais valor para o homem. A partir desta questão levantada Heidegger coloca a quarta sentença sobre a arte: "a arte é o contramovimento insigne contra o niilismo" (Idem, p. 68). A quinta e última sentença de Heidegger sobre a arte diz o seguinte: "a arte tem mais valor do que a verdade" (Idem, p. 70). Dentro da interpretação sobre Vontade de poder como arte, a quinta sentença é a conclusão máxima que Heidegger levanta em seu discurso sobre a arte, o restante daquilo que irá propor daí por diante, justifica e embasa essa sua proposição.

No entanto, antes de considerer a proposição sobre a arte como esquematização do mundo, se faz necessário abordar duas ideias centrais do pensamento nietzscheano a respeito da arte. A primeira delas é a ideia de inebriez como estado estético e como força conformadora da realidade, e a segunda é a ideia do estilo elevado da arte onde Heidegger explora a contradição entre clássico e romântico que o próprio Nietzsche vai contrapor em 
IGOR LOCROIX

seus fragmentos. É de fundamental importância a abordagem dessas duas ideias, uma vez que a compreensão acerca do processo de esquematização que ocorre por meio da arte deve necessariamente passar por ambas. Heidegger compreende estética como "a consideração do estado sentimental do homem em sua relação com o belo, é consideração do belo na medida em que ele se encontra em ligação com o estado sentimental do homem” (Idem, p. 72).

Estética é uma maneira do homem perceber o mundo, portanto ela tem influência no seu modo de pensar, e além disso está ligada à história da arte. Neste ponto de compreensão histórica, é introduzido seis fatos fundamentais da estética. O primeiro deles explora a ideia de que a grande arte grega permanece sem uma meditação conceitual pensante que corresponda a ela, o que não significa dizer que tal meditação teria de se confundir com uma estética. O que os gregos tinham era um saber claro, tão originariamente desenvolvido, e uma tal paixão pelo saber, não careciam de nenhuma estética em meio a essa claridade. $O$ segundo fato traz a concepção de que no mundo grego, a grande arte e a grande filosofia corriam, a princípio, paralelamente. A estética só começou aí, por sua vez, no instante em que a grande arte, assim como a grande filosofia chegaram ao seu fim. $\mathrm{O}$ ente é aquilo que irrompe e vem à tona, neste context, crescendo a partir de si mesmo e sem ser impelido a nada, o que retorna a si e passa: a vigência que irrompe e retorna a si. O terceiro fato fundamental para a história do conhecimento sobre a arte aponta para o começo da modernidade. O homem e o seu livre saber em torno de si mesmo e de sua posição no interior do ente torna-se, agora, o lugar da decisão quanto ao modo como o ente precisa ser experimentado, determinado, configurado. Paralelamente à formação do domínio da estética e da relação estética com a arte, dá-se a decadência da grande arte no sentido mencionado. O quarto fato desenvolve a ideia de que no instante histórico em que a estética conquista o seu ápice, a sua maior amplitude e o seu maior rigor possíveis, a grande arte chega ao fim. A consumação da estética adquire sua grandeza do fato de conhecer e expressar esse fim da grande arte com tal. A estética derradeira e maximamente grandiosa do Ocidente é a estética de Hegel. Em vista do declínio da arte ante sua essência, o século XIX ainda se arrisca uma vez mais e busca realizar a obra de arte integral. Esse esforço está ligado ao nome de Richard Wagner. Nietzsche captura da ação de Wagner o arrebatamento que impelia para o todo a partir da embriaguez, o que ele designou o dionisíaco. $\mathrm{O}$ esforço em busca pela obra de arte integral é entendido por como o quinto fato fundamental a partir da história da estética.

O que Hegel expressou sobre a arte - o fato de ela ter perdido o poder como configuração e preservação normativa do absoluto - foi reconhecido por Nietzsche em relação aos valores supremos e é considerado por Heidegger como o sexto e último fato histórico da 
IGOR LOCROIX

estética. A posição fundamental de Nietzsche em relação à arte como realidade histórica é determinada de maneira mais próxima, e, juntamente com isso, o modo de seu conhecimento e de seu querer conhecer a arte: a estética como fisiologia aplicada. A compreensão da inebriez como estado estético deve necessariamente passar por esta apreensão histórica, mas principalmente pela maneira como Heidegger interliga os fatos de maneira a estabelecer no final a estética como fisiologia, como percepção corporal e espiritual, a partir das determinações nietzcheanas acerca da arte. O próprio Nietzsche é quem melhor descreve o estado estético da inebriez:

\begin{abstract}
Para que haja a arte, para que haja um fazer e uma visualização estética, é incontornável uma precondição fisiológica: a inebriez. A inebriez precisa ter elevado primeiramente a excitabilidade de toda a máquina: senão não se chega à arte. Todos os modos mais diversamente condicionados da inebriez ainda possuem a força para isso: antes de tudo, a inebriez da excitação sexual, a mais antiga e originária forma de inebriez. Do mesmo modo, a inebriez que nasce como consequência de todo grande empenho do desejo, de toda e qualquer afecção forte; a inebriez da festa, do combate, dos atos de bravura, da vitória, de todo e qualquer movimento extremo; a inebriez da crueldade; a inebriez na destruição; a inebriez sob certas condições metereológicas, por exemplo, a inebriez primaveril; ou sob a influência de narcóticos; por fim, a inebriez da vontade, a inebriez de uma vontade acumulada e dilatada (Idem, p. 89).
\end{abstract}

Inebriez não é meramente estar bêbado, ou sob a influência de drogas, é antes de tudo um estado físico e mental, onde há a concentração de sentimentos e sensações acerca do mundo. É uma elevação consciente, uma predisposição frente à percepção daquilo que nos afeta. Inebriez é uma mudança de caráter frente à realidade que possibilita a elevação dos sentimentos rumo a novas perspectivas de vida. Neste ponto Heidegger aborda dois conceitos fundamentais para a obra de Nietzsche que estão presentes desde sua primeira publicação: apolíneo e dionísiaco, o onírico e o encantamento, as duas forças artísticas da natureza. "A convergência dos dois na unidade de uma figura é o nascimento da suprema obra de arte grega: a tragédia" (Idem, p. 95). A inebriez aparece, portanto, em contraposição ao "deleite desinteressado" kantiano, ela aparece como excitação, estimulação.

A partir deste estado inebriado o artista é capaz de, por meio da forma, corporificar a beleza e, desta maneira, transferir esse estado estético ao observador da obra de arte. $\mathrm{O}$ artista inebriado é capaz de estabelecer um percurso perceptivo para a elevação da vida. Inebriez significa a conquista mais clara e distinta possível da forma, nesse sentido a forma é esquematização inebriada em direção à beleza. Uma multiplicidade de características estão associadas a ideia de inebriez, sendo que a mais antiga e originária é a inebriez sexual (Idem, REVISTA DE ESTÉTICA E SEMIOTICA, BRASÍLIA, V. 2, N. 1 P. 16 - 32, JAN./JUN. 2012. 
IGOR LOCROIX

p. 105), que está presente tanto no estado apolíneo quanto no dionísico. A obra de arte é sempre nesse sentido sexual, com vontade de parir, de gerar novos entes, ou transformar os existentes. Para Nietzsche a inebriez é uma espécie de rotina que possibilita a criação. É interessante perceber o movimento que a filosofia do pensador faz quando vai de conceitos abstratos para conceitos mais cotidianos, mais ligados a uma vida mundana. Talvez, tenha sido da percepção desse tipo de movimento que Heidegger possa tê-lo entendido como um 'filósofo da vida'.

Heidegger, de certa maneira, diz que Nietzsche percebe um todo estético, da realidade artística quando interpreta, por exemplo, a multiplicidade do contexto de criação artística. A multiplicidade enquanto uma espécie de universo que não pode ser compreendido em uma totalidade absoluta, mas que justamente pelo fato de existir em múltiplas instâncias, possibilita a compreensão de um todo em coexistência, mesmo que em conflito, ou contradição. A partir desse universo, a partir “das massas” como o próprio Nietzsche define, é possível emergir a distinção, por meio de uma lógica, que estabelece uma beleza. A conjunção desses três pontos possibilita a compreensão do estilo elevado da arte, do conhecimento, da criação. Estilo elevado é a manifestação mais apurada, melhor objetivada, aquela que mais se aproxima de um ideal de criação. É inebriez por excelência, o gozo. É a plenitude da concepção, talvez, o presente onde o criador e o receptor da obra de arte estejam mais próximos, ou quem sabe, confundidos em um só.

Mais uma vez Heidegger explora sua percepção histórica ao relacionar clássico e romântico como caminhos possíveis para a produção artística. Ideais que não são opostos, ou não se constróem necessariamente em contradição, mas em uma forma de equivalência e que no fim são apenas parâmetros de apreensão da própria arte. O objetivo de Nietzsche é abarcar o que é a obra de arte integral sem necessariamente explorar as possíveis contradições entre clássico e romântico. A compreensão de clássico não tende a um classicismo, mesmo que o estilo elevado esteja ligado à tragédia grega ou as suas interpretações posteriores, como a ópera de Wagner. Estilo elevado tende à essência do trágico, à catarse, à esquematização plena, e não a uma qualificação do que é clássico ou romântico.

Depois de abordar a questão do estilo elevado, Heidegger parte para uma nova etapa de seu discurso que servirá para, além de justificar teoricamente o argumento que irá desenvolver a partir daí, relançar sua abordagem em confronto ao posicionamento nietzcheano frente à tradição metafísica. Constrói uma série de apontamentos sobre a obra de Platão, utilizando a República, O Fedro, explorando a relação entre verdade e arte, ideia e mimese, e também a inversão do platonismo estabelecida pela filosofia de Nietzsche. Estabelece também uma 
IGOR LOCROIX

gradação dos principais pontos históricos onde houve uma reflexão sobre a ideia de mundo verdadeiro, no sentido do platonismo. A escala se inicia com Platão, passa por Kant, pelo Idealismo Alemão, por Nietzsche, até chegar ao depois de Nietzsche, que no fim seria a própria posição de Heidegger em meio à tradição metafísica. Sendo o objetivo principal desvelar a ideia de que o "sensível não é mais o 'aparente', não é mais o obscurecido, ele é o único real, portanto, o "verdadeiro"” (Idem, p. 189).

No último trecho de Vontade de Poder como Arte, Heidegger explora, como conclusão para seu discurso sobre a arte, a ideia de que todo o ente é sensível. Ideia que seria resultante de uma conjunção de conceitos basicamente orientados pela perspectiva da inversão do platonismo, onde o mundo supra-sensorial tem mais valor que o mundo sensível, ou seja, é mais verdadeiro. O filósofo de Meßkirch propõe que o ente, o real ou a realidade, deve ser determinado de maneira nova, a partir da compreensão da filosofia de Nietzsche. O exemplo utilizado é do orgânico e do inorgânico como dois âmbitos pertencentes à realidade, à vida, sem uma hierarquia entre um e outro. Orgânico no sentido de uma pluralidade perspectivística interna que é ela mesma um acontecimento (Idem, p. 188). O inorgânico não é colocado como o oposto, mas como tudo o que não é possível qualificar, muito devido à enorme quantidade. Leis mecanicistas são estabelecidas por finalidade cálculo que possibilita fundamentar teorias científicas por exemplo.

Neste sentido, "A arte como transfiguração é mais elevadora da vida do que a verdade como fixação de uma aparição" (Idem, p. 192). Em outros termos, se pode dizer que a criação inebriada em direção à beleza catártica tem mais valor do que a verdade que esconde a real ignorância sobre a compreensão a respeito do mundo, o velamento a respeito da totalidade do todo.

\section{ARTE E CONHECIMENTO}

Na terceira parte de Nietzsche - Volume I, Heidegger faz uma reflexão sobre a vontade de poder como conhecimento, a compreensão que se tem é de que não há uma diferenciação de fato entre arte e conhecimento, sendo a principal maneira de justificar isso por meio da

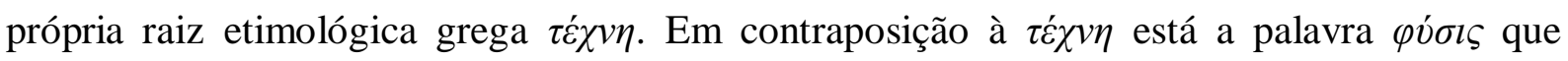
significa natureza, e é entendida pelos gregos como o ente mesmo na totalidade. É a $\tau \dot{\varepsilon} \chi v \eta$ sobre a $\varphi v ́ \sigma ı \varsigma$ o próprio saber diante do mundo, a esquematização do caos. 
IGOR LOCROIX

Ainda, Nietzsche fala em biologia da razão, a razão e lógica condicionadas biologicamente no animal homem, por isso podemos afirmar a filosofia fisiológica, pois ela é racional mas oriunda da própria biologia humana, não de um mundo supra-sensorial separado do corpo no todo. Esse todo que não é abarcável em sua totalidade é compreendido a partir do ponto de vista do caos, a desorganização passível de ser organizada de acordo como leis e normas. Além disso, a própria organização pode também ser reorganizada de acordo com a realidade em constante transformação. A constante transformação, as coisas do mundo em permanente mudança - pois os entes instantes em relação de interação se alteram também devido a própria ação de interagir em multiplicidade - faz carecer de um arcabouço que nos auxilie frente à pratica da vida.

Sem querer distanciar muito do âmbito heideggeriano, mas com relação a este ultimo ponto se pode comparar a ideia de carecimento prático com a ideia de práxis presente em Marx. Também, atua nesta comparação o procedimento de inversão proposto por Heidegger sobre Nietzsche. Enquanto Marx vê a prática durante a própria produção de um processo industrial vigente em diversas partes do mundo, Nietzsche vê a prática enquanto aquilo que carece e possibilita a criação pela construção de esquemas perspectivísticos frente ao que não se controla, ao desconhecido, ao que nos é e está velado. Ambas as visões ocorrem acerca de uma realidade equivalente, talvez a primeira social e a outra individual, ou subjetiva, mas ambas fundamentadas em uma realidade específica.

$\mathrm{Na}$ medida em que se observa o horizonte de pensamento, se percebe a carência de esquemas que conformem uma perspectiva frente ao mundo em transformação. A partir desse carecimento se forma cálculos e acordos, se faz poesia e comandos que ajudam a lidar com a realidade. Ainda, se faz a arte a partir daí, poetizamos por meio da razão.

Ao concluir a parte $A$ vontade de Poder como Conhecimento, Heidegger estabelece a ideia de que o pensamento é construtivo, e desenvolve uma imagem onde compara o pensamento à própria construção do espaço.

\footnotetext{
O pensamento construtivo é, ao mesmo tempo, excludente. [...] A construção como erigir precisa ao mesmo tempo decidir constantemente sobre medidas e alturas, e, por conseguinte, excluir e formar para si mesma pela primeira vez o campo do jogo, no qual ela erige suas medidas e alturas e abre suas visadas. A construção atravessa decisões (Idem, p.30).
}

Assim, a arte também se conforma, destruindo, violentando aquilo que é natural para transformá-lo de acordo com uma consciência elevada. "Construir... tem em vista o erigir e o levantar, ir em direção à altura...” (Idem, p. 31), é ação inebriada na medida em que busca a 
IGOR LOCROIX

elevação. O autor fixa essa comparação afirmando que este é um caminho frente ao que nos é está velado. Ainda, a arte é também na medida do conhecimento uma construção rumo ao desconhecido.

\section{BIBLIOGRAFIA}

HEIDEGGER, Martin. Nietzsche - Volume I. Tradução Marco Antônio Casanova. Editora Forense Universitária, Rio de Janeiro, 2010 A.

\section{REFERÊNCIAS}

ARTIGAS, Vilanova. Caminhos da Arquitetura. Cosac \& Naify Edições, São Paulo, 1999. BOBBIO, Norberto; MATTEUCCI, Nicola; PASQUINO, Gianfranco. Dicionário de Política

- Volume I. Tradução Carmen C. Varriale, Gaetano Lo Mônaco, João Ferreira, Luís Guerreiro Pinto Cacais e Renzo Dini. Editora Universidade de Brasília, Brasília, 1998.

HEIDEGGER, Martin. Ensaios e Conferências. Tradução Emmanuel Carneiro Leão, Gilvan Fogel e Marcia Sá Cavalcante Schuback. Editora Vozes, Petrópolis, 2001 A.

HEIDEGGER, Martin. Nietzsche - Volume II. Tradução Marco Antônio Casanova. Editora Forense Universitária, Rio de Janeiro, 2010 B.

KOTHE, Flávio René. Ensaios de Semiótica da Cultura. Editora Universidade de Brasília, Brasília, 2011.

MARX, Karl. O Capital: crítica da economia política. Livro I. Tradução Reginaldo Sant'Anna. Editora Civilização Brasileira, Rio de Janeiro, 1968.

NIETZSCHE, Friedrich Wilhelm. Além do bem e do mal - Prelúdio de uma filosofia do futuro. Tradução Armando Amado Júnior. Editora WVC, São Paulo, 2001.

$$
\text { Fragmentos Póstumos. Tradução Flávio René Kothe. }
$$

Editora Universidade de Brasília, Brasília, 2002.

Gaia Ciência. Tradução Paulo César de Souza.

Companhia das Letras, São Paulo, 2001 B.

.A origem da tragédia. Tradução Joaquim José de Faria.

Editora Centauro, São Paulo, 2008.

PLATÃO. Greater Hippias. Tradução Walter Rangeley Maitland Lamb. Harvard University Press, Cambridge, 1925.

REVISTA DE ESTÉTICA E SEMIOTICA, BRASÍLIA, V. 2, N. 1 P. 16 - 32, JAN./JUN. 2012. 
IGOR LOCROIX

ANEXO

Esta parte do presente trabalho é uma breve reflexão em forma de fichamento de ideias, conceitos que definitivamente foi feita a partir da interpretação de partes da obra em questão. $\mathrm{O}$ intuito é registrar apontamentos acerca do todo e da relação entre o fragmento e o pensamento. A escrita desta parte segue o exemplo de Nietzsche, que se permite registrar em fragmentos sem grande sistematização, o substrato de um pensamento que muitas vezes surge da intuição ou da percepção de determinados acontecimentos.

\section{FRAGMENTOS}

01. A obra de arte como aquilo que sua beleza, lógica, esquematiza o caos e permite ao ente estante um momento de desvelamento diante do mundo. Precisamos tomar cuidado com as palavras e a maneira como ordenamos as coisas, pois a partir disso o desvelamento diante do devir é definido, de um lado o bem de outro lado o mal. A filosofia nietzscheana propõe ir além disso.

02. A tragédia, portanto, acontece sem nos darmos conta, a proposição aqui é de que a tragédia acontece quando o caos, ou a falta de perspectiva, se apropria do próprio desvelamento, destruindo-o, acabando com o que se desvela. O caos nesse sentido é iminente e permanente. A perspectiva é que é temporária e suscetível, frágil. A aparência é própria ruptura/destruição, na medida em que ela rompe o próprio caos. A perspectiva utiliza o caos como matéria-prima, nesse sentido é o próprio caos.

03. De maneira semelhante ocorre a filosofia de Nietzsche com relação à sua inversão do platonismo, da chamada tradição metafísica. Na medida em que inverte a noção do platonismo, não quer dizer que ela escape da metafísica. Conforme Heidegger, Nietzsche é o filósofo do acabamento da metafísica, acabamento não como fim da metafísica, mas como aprimoramento, como algo que transporta a metafísica a uma etapa superior, capaz de reavaliar o que até então foi produzido e propiciar um novo caminho para a metafísica.

04. A visão da obra de arte é metafísica, uma vez que a percepção, ou mais especificamente a perspectiva que o indivíduo tem da obra faz parte de uma esquematização que é metafísica. No entanto, uma metafísica invertida, no sentido de não mais advir de um mundo supra-sensorial, chamado vulgarmente mundo das ideias, mas de um mundo sensível, das percepções. 
IGOR LOCROIX

05. A obra de arte elevada surge da inebriez dos sentidos, inebriez que no caso não é mera bebedeira, mas a concentração dos sentidos de maneira quase racional, organizada. A obra é constitutiva de afeto, sentimentos e paixão, uma gradação de sentimentos que definem a obra de arte em estágios de apreensão - cada um de acordo com níveis de inebriez - até o que Nietzsche define como estilo elevado, que seria onde a obra de arte é mais marcante.

06. A obra de arte do estilo elevado é aquela que possui determinadas qualidades tais como lógica, beleza e distinção. Organizada de maneira a expor de maneira mais explícita os sentimentos do próprio artista que produz a obra e é capaz de expressar de maneira mais contundente os próprios sentimentos para o indivíduo que percebe e interpreta a obra.

07. Nesse ponto a forma é fundamental para a apreensão da obra de arte. A forma é a expressão da inebriez, a forma como a esquematização que possibilita a percepção do indivíduo. A obra de arte é veículo dos sentimentos por meio da forma. A arte, enquanto configuração da vontade de poder, é entendida na obra de Nietzsche a partir do ponto de vista do artista. Nietzsche propõe uma estética masculina, de quem produz a obra em contraposição à estética feminina que até então imperou por meio daqueles que recebiam a obra de arte.

08. Nietzsche propõe a ideia do filósofo-artista como sendo aquele que não somente continua a tradição, ou, de certa forma, apenas dá prosseguimento a tudo aquilo que já foi dito por outros filósofos anteriores, mas como aquele que é capaz de dar forma a sensações por meio de sua filosofia. O filósofo-artista cria da mesma maneira como o pintor ou o poeta, organizando o mundo sensível por meio da racionalização dos pensamentos, ideias e conceitos de sua filosofia.

09. Conhecimento e arte não se diferenciam a partir desse ponto de vista, ambos são equivalentes, fazem parte da mesma configuração da vontade de poder que é a principal característica do ente estante. Nesse sentido ambos fazem parte do conceito de equivalência que define o conhecimento. Equivalência entendida como um processo de correção da verdade.

10. Isso é basicamente a ideia que Heidegger coloca quando fala sobre o outro caminho que a filosofia de Nietzsche indica, entra aí a perspectiva além do bem e do mal. Interessante notar que Heidegger articula isso sem uma conclusão definitiva. A obra inacabada de Nietzsche, em verdade uma obra fragmentária, produzida em paralelo à obra publicada do filósofo, é articulada de maneira em que Heidegger propõe sua própria filosofia por meio da voz de Nietzsche. 


\section{IGOR LOCROIX}

11. De forma comparativa poderíamos adotar a obra de Platão, Hípias Maior, onde Sócrates cria um personagem fictício para poder dar voz aos próprios conceitos sobre a beleza e, desta maneira, poder convencer melhor a mente de Hípias.

12. Nessa obra de Platão, Sócrates não chega a uma conclusão sobre a definição de beleza, no fim diz apenas que as coisas belas são difíceis. A verdade sobre a beleza permanece em aberto. A lição maior é sobre a própria desconstrução de conceitos que muitas vezes permanecem estagnados como verdades absolutas.

13. A própria relação entre verdade e arte no texto de Heidegger é explorada quando Heidegger lança mão de um dos fragmentos de Nietzsche que deixa explícito o horror de Nietzsche com relação a dicotomia que é levantada quando relacionamos os dois. A arte enquanto construção e a verdade enquanto fixação não poderiam confluir ou se correlacionar. A contradição entre ambas é ontológica no sentido do próprio devir do ente estante em direção ao ser-estar.

14. Para exemplificar Heidegger explora a ideia de conhecimento enquanto a construção dos espaços. O conhecimento ergue seus conceitos se apropriando e fechando os vazios da mesma maneira como construimos as paredes sobre o terreno. Ao mesmo tempo que construimos, destruimos o espaço precedente e erguemos nossa perspectiva diante do horizonte. O conhecimento também enquanto elevação do olhar, da percepção sobre o mundo.

15. A proposição é de que a obra de arte é o meio pelo qual é possível dominar as contradições, por meio da percepção sensível que faz parte do biologismo que Nietzsche propõe. Isso não é mero pressuposto corporal, ou sobreposição do corpo sobre a mente, o biologismo é entendido no sentido da esquematização sobre o caos, da construção sobre o vazio, o cérebro é parte constituinte do corpo, a razão, assim como o instinto para o animal, é entendida como aquilo que demarca todo ente estante humano. A razão humana é instintiva, constituinte.

16. A contradição seria dominada na obra de arte na medida em que é estabelecida uma perspectiva, um olhar sobre o horizonte é elevado diante do caos. A obra de arte constitui nesse ponto o prazer para quem a usufrui, algo que é capaz de ascender o devir do ente.

17. A ideia de desvelamento que Heidegger propõe, talvez se relacione à concepção de Solger de domínio das contradições que a obra de arte estabelece. O desvelamento como um momento em que é possível lançar uma perspectiva sobre o mundo e dessa forma estabelecer uma relação como aquilo que nos é velado, um momento de iluminação, equivalente ao momento de prazer. 
IGOR LOCROIX

18. O pintor quando representa uma determinada perspectiva, uma mesa, ou no exemplo clássico da cama, ou mesmo um rosto, ele representa apenas um dos lados do objeto. Não é capaz de abarcar o todo da perspectiva, não é capaz de mostrar o outro lado, nesse sentido a pintura é um fragmento da perspectiva, o todo só poderia ser apreendido de forma imaginativa, por meio de pressuposições, de uma lógica daquilo que existe enquanto uma ideia preexistente. A pintura nesse sentido seria o próprio reflexo do platonismo, platonismo enquanto mero fragmento do todo da filosofia de Platão.

19. O todo que é constituído por uma família, onde diferentes membros representam diferentes vozes, pode ser entendido também como um todo constituído de fragmentos. A valoração estabelecida dentro de uma família ocorre na medida em que as diferentes vozes negociam seus limites. O problema de rompimento dos fragmentos, neste caso a ruína do todo, acontece na medida em que não é possível negociar, onde não é possível, ou não é permitido, exercer sua própria voz, sua autonomia, onde há de certa forma um totalitarismo.

20. A separação de uma família seria no caso a fragmentação do todo que existia com a união dos fragmentos. A questão é que durante a união, a valoração do fragmento se altera conforme o todo e no momento da separação o fragmento carrega consigo mesmo valores do todo. O fragmento que já fez parte de um todo leva em consideração os valores que foram construídos durante a existência desse determinado todo.

21. O cristianismo seria no caso a fragmentação de um todo filosófico que por censura foi separado. O totalitarismo cristão fragmentou um todo onde a polifonia de perspectivas podia existir sem conflito. O sentido dos fragmentos, no entanto, não se perde, apenas a possibilidade de diálogo. Apenas um novo olhar, uma nova interpretação é estabelecida, que no caso do cristianismo é dogmática e com tendência absolutista.

22. Heidegger quando explora a obra fragmentária de Nietzsche parte da construção de um todo por meio do diálogo de diferentes fragmentos. A comparação com a família seria neste caso não em relação à separação, mas com a constituição de uma família. A união de fragmentos com o intuito de constituir um discurso próprio, com determinado fim. A união de uma família também é a constituição de um discurso que se posiciona em meio ao caos. A constituição de uma família também é, nesse sentido, um processo semelhante à esquematização frente ao desconhecido.

23. Enquanto existe um grupo familiar, há uma organização, quando há o rompimento desse grupo, a morte ou a separação, essa organização é desestruturada, em muitos casos surge a necessidade de estabelecimento de uma nova organização. A ruptura precede a reorganização também no âmbito artístico, a ruptura com o passado estabelecida por 
IGOR LOCROIX

determinados movimentos artísticos, é apenas como justificativa para novas organizações que, na maioria dos casos, não são inéditas, mas meras reorganizações de partes que já existiam.

24. A fragmentação da obra de Platão ocorre nesse sentido de maneira a se atingir determinados objetivos pela apropriação de conceitos de uma obra filosófica que no caso atuou como parâmetro para o todo da metafísica. Nietzsche, de acordo com Heidegger, lança uma nova possibilidade para a metafísica oriunda do platonismo. E, nesse sentido ela rompe diversas ideologias, fragmentariza as ideologias, por meio do fragmento. O próprio estilo já indica a intenção da filosofia nietzscheana. A visão, portanto, é de que o fragmento enquanto sistema não é ingênuo, desprovido de intenção. Há no uso do fragmento por parte de Nietzsche um desvelamento a respeito da própria vontade do filósofo em romper com os valores dominantes. A fragmentação, a desestruturação da ideologias, seria imprescindível para a revaloração e a possibilidade de existência do supra-homem.

25. Heidegger é o filósofo que é capaz de sistematizar a obra fragmentária de Nietzsche em torno de famílias de fragmentos sobre temas semelhantes. Nietzsche, nesse sentido, como o criador de um universo que possibilita a organização aberta segundo determinada intenção. A obra de arte totalizante entra nesse âmbito também no sentido de possibilitar o diálogo entre partes separadas dentro de um resultado comum.

26. A percepção como estabelecimento de valor de um sujeito diante do objeto. Por aí a percepção do sujeito também é fragmentária. Percebemos segundo os valores que priorizamos. O sujeito não é capaz de perceber a totalidade do todo, filtra a apreensão do mundo de acordo com os valores que lhe são intrínsecos. A revaloração atuaria no sentido de possibilitar ao indivíduo novas percepções, uma maior abertura para a apreensão do mundo.

27. O todo de obras de um artista também poderia ser compreendido como o conjunto de fragmentos que juntos formam a história do desenvolvimento artístico, conceitual, formal, de um artista. Até mesmo dentro desse todo é possível valorar a qualidade das fases de um artista. Desde a perspectiva do todo, uma parte individual poderia ser compreendida como fragmento, assim como os estilhaços de um objeto quebrado. Uma vez reunidos os estilhaços temos o todo novamente, mesmo que não em sua totalidade original plena.

28. A multiplicidade que tende ao nada, não necessariamente é vazia, mas faz parte de um nada construtivo, passível de ser configurado. Do nada, ou caos, surge a construção da perspectiva. A multiplicidade fértil. A falta de sistematização é útil, pois ela abre espaço para a construção. 
IGOR LOCROIX

29. Será o fragmento uma ruptura com o todo? O pensamento em fragmentos será indício de loucura? A percepção por fragmentos, será ela capaz de construir a ideia de todo? Será que o sujeito que percebe está sempre em fragmentos diante do mundo, dos objetos?

30. Pensar o fragmento, ou pensar em fragmentos pode revelar um modo de vida que admite a destruição como parte imprescindível da própria construção do pensamento. Então o caminho do além do bem e do mal não significa colocar-se afastado do bem e do mal, mas admitir essa coexistência e colocar-se em uma situação onde não haja limitações morais quanto a essa dicotomia.

31. O problema é a definição de tal postura enquanto ao que é normal, ou seja, sobre a possibilidade de qualificar tal modo de vida além do bem e do mal enquanto normal. A questão então recai no posicionamento diante dos frutos da filosofia de Platão, em especial da religião cristã.

32. As próprias religiões, nesse sentido, são na medida em que se posicionam contra o fragmento, na medida em que constróem um todo por meio da cosmogonia e da moral. A desconstrução do todo é combatida no sentido de fazer permanecer o valor construído, nesse sentido, impossibilitando a vontade de poder do sujeito, impossibilitando a revaloração. 